\title{
Efeito da técnica de coleta e do estágio do ciclo estral na recuperação de oócitos de boa qualidade em felinos e caninos domésticos*
}

\section{The effect of recovery technique and stage of estrous cycle on the recovery of good quality oocytes in domestic felines and canines}

\author{
Rodrigo Oliveira Cunha, ${ }^{* *}$ Viviane Lopes Brair, ${ }^{* *}$ Paulo Sergio Cerqueira Rangel, ${ }^{* *}$ Isabela Regis Pereira, ${ }^{* * *}$ \\ D’angelo Carlo Magliano, ${ }^{* * *}$ Ribrio Ivan Tavares Pereira Batista, ${ }^{* *}$ Joanna Maria Gonçalves Souza-Fabjan**
}

\begin{abstract}
Resumo
A obtenção de oócitos de boa qualidade é essencial para o sucesso de diversas biotécnicas reprodutivas. Objetivou-se determinar o efeito de duas técnicas na recuperação de oócitos de boa qualidade em gatas e cadelas em diferentes estágios reprodutivos. Foram utilizados 43 pares de ovários de gata e 35 de cadela após realização da ovariosalpingohisterectomia eletiva. A fase do ciclo estral foi classificada em inativa, folicular ou luteal. Os ovários da fase folicular foram divididos em três grupos: PUN) punção dos folículos com agulha; PUN+FAT) fatiamento do mesmo ovário já puncionado; e FAT) fatiamento do segundo ovário. Os ovários das fêmeas em fase luteal e inativa foram submetidos ao FAT. Foram obtidos no total 974 oócitos ( 23/animal) nas fêmeas felinas e 940 ( 27/animal) nas caninas. O fatiamento recuperou número superior $(P<0,05)$ de oócitos. Não houve diferença $(P>0,05)$ entre as técnicas de coleta na qualidade de estruturas recuperadas. A quantidade de oócitos recuperados em cada fase foi similar $(P>0,05)$. Contudo, a fase inativa foi superior à luteal $(P<0,05)$ e semelhante à folicular na quantidade de oócitos de boa qualidade em gatas e não houve diferença em cadelas. Conclui-se que o fatiamento recupera maior quantidade de oócitos, não influenciando em sua qualidade. As fases inativa e folicular recuperam maior quantidade de oócitos de boa qualidade em gatas e não afetam a recuperação em cadelas. Portanto, para otimizar o uso das biotecnologias, deve-se levar em consideração o estágio do ciclo estral em fêmeas felinas e a técnica de coleta utilizada na recuperação de oócitos.
\end{abstract}

Palavras-chave: Biotecnologia da Reprodução, Cadela, Gata, Oócito, Técnica de coleta.

\begin{abstract}
The recovery of good quality oocytes is essential for the success of various reproductive biotechniques. The aim of this study was to determine the effect of two techniques on the recovery of good quality oocytes in queens and bitches at different reproductive stages. A total of 43 pairs of ovaries of queens and 35 of bitches after elective ovariosalpingohisterectomy were performed. The estrous cycle phase was classified as inactive, follicular or luteal. The ovaries of the follicular phase were allocated into three groups: PUN) puncture of the follicles with a needle; PUN + SLI) slicing of the same ovary already punctured; and SLI) slicing of the second ovary. The ovaries of luteal and inactive females were submitted to SLI. A total of 974 oocytes ( 23/animal) were obtained in feline females and $940(\sim 27 /$ animal) in canines females. The SLI technique recovered superior number $(P<0.05)$ of oocytes. There was no difference $(P>0.05)$ between the collection techniques in the quality of recovered structures. The number of oocytes recovered in each phase was similar $(P>0.05)$. However, the inactive phase was higher than luteal $(P<0.05)$ and similar to the follicular phase in the quantity of good-quality oocytes in queens and there was no difference in bitches. In conclusion, it is preferable to perform the slicing technique to recover more oocytes in both species. Moreover, in queens it is possible to obtain good quality oocytes in the inactive phase and in bitches the estrous cycle phase does not influence the quality.
\end{abstract}

Keywords: Biotechnology of Reproduction, Bitch, Cat, Oocyte, Recovery method.

\section{Introdução}

Nos últimos anos, tem-se observado um crescente interesse em técnicas que possibilitem um maior aproveitamento do material genético oriundo de machos e fêmeas de diferentes espécies. Os gatos e cães domésticos são os animais pet mais numerosos do mundo. O estreitamento da relação do homem com esses animais nos últimos anos contribuiu para que houvesse um aumento no interesse reprodutivo dessas espécies, principalmente a canina (Faraco, 2008; Binsfeld et al., 2014; Jewgenow et al., 2017). Por outro lado, os felinos domésticos ainda são descendentes próximos de outros

\footnotetext{
*Recebido em 25 de novembro de 2018 e aceito em 14 de outubro de 2019.

${ }^{*}$ Faculdade de Veterinária, Universidade Federal Fluminense, Av. Vital Brasil Filho, 64, CEP 24230-340, Niterói, RJ, Brasil

${ }^{* * *}$ Faculdade de Medicina Veterinária, Escola de Ciências da Saúde, Universidade do Grande Rio, Rua Prof. José de Souza Herdy, 1160 - 25071-202, Duque de Caxias-RJ, Brasil

****Instituto Biomédico, Universidade Federal Fluminense, Rua Hernani Melo, 101, 24210-130, Niterói, RJ, Brasil.
} 
felinos selvagens (Driscoll et al., 2007). Isto torna possível a utilização do gato doméstico como modelo experimental para os felídeos selvagens, que estão em sua maior parte ameaçados de extinção (Moro et al., 2015). Existem diversas biotécnicas reprodutivas que podem ser aplicadas para a preservação de espécies ameaçadas (Uchikura et al., 2010) e para a melhoria do desempenho reprodutivo (Luvoni et al., 2005).

A obtenção de oócitos de boa qualidade, que apresentem competência ao desenvolvimento, é essencial para o sucesso das biotécnicas da reprodução que envolvam a produção in vitro de embriões e clonagem (Baldassare et al., 2002; Pereira et al., 2013). A obtenção desses oócitos pode ser feita por duas técnicas, punção (PUN) folicular e/ou fatiamento (FAT) do ovário. A maior parte dos estudos utiliza o FAT (Hermansson et al., 2007; Sowińska et al., 2017), em função do pequeno tamanho dos ovários. Apesar de não haver relatos de comparação direta entre as técnicas nas espécies felina e canina, na espécie caprina, o FAT possibilitou a obtenção de maior número de oócitos em relação à PUN. Porém, a última foi capaz de preservar melhor a estrutura oocitária e número de camadas de células do cumulus, indicadores de qualidade oocitária (Martino et al., 1994). Sabese que a principal forma não invasiva para avaliar a qualidade dos oócitos é pela sua homogeneidade do ooplasma e número de células do cumulus (Lasienë et al., 2009).

Com relação ao ciclo estral, as gatas são classificadas como poliéstricas estacionais com fotoperíodo positivo, dependendo principalmente da latitude da região. Desta forma, as gatas podem ciclar durante todo o ano, mesmo que haja redução da atividade ovariana ou ainda terem atividade folicular durante o anestro (Brown, 2011). Já a cadela é classificada como monoéstrica não estacional, com o intervalo interestro variando de seis meses a um ano, em média sete meses (Farstad, 2000; Johnston et al., 2001). Desta forma, este estudo objetivou identificar o potencial de recuperação de oócitos de boa qualidade a partir de duas técnicas distintas em gatas e cadelas em diferentes estágios do ciclo estral.

\section{Material e métodos}

\section{Ética e bem-estar animal}

Este projeto foi aprovado pelo Comitê de Ética em Uso de Animais (CEUA) da Universidade do Grande Rio (UNIGRANRIO) ( $n^{\circ}$ 003/2017). Além disso, o mesmo seguiu as normas adotadas pela Sociedade Brasileira de Ciências em Animais de Laboratório.

\section{Data, local e animais experimentais}

O estudo foi realizado de Abril de 2017 à Janeiro de 2018, no Hospital-Escola de Medicina Veterinária Prof. Allan Kardec, localizado na UNIGRANRIO, na cidade de Duque de Caxias, Estado do Rio de Janeiro (latitude $22^{\circ} 47^{\prime} 19^{\prime \prime S}$, longitude 4318'21"O).

Foram utilizados 43 pares de ovários de fêmeas da espécie felina e 35 pares de ovários de fêmeas da espécie canina, de raças variadas e livres de alterações sanitárias, após a realização da ovariosalpingohisterectomia (OSH) eletiva, por motivos pessoais do proprietário ou por indicação médico-veterinária, ou seja, por razões não relacionadas a este estudo.

\section{Desenho experimental}

\section{Experimento 1 - Cadelas}

Os ovários das fêmeas da espécie canina eram coletados após a $\mathrm{OSH}$, separados de acordo com a idade e o porte do animal em: pequeno (até $9 \mathrm{~kg}$ ) e médio porte $(10-25 \mathrm{~kg}$ ) (Müller, 2007) e imediatamente submetidos a avaliação morfológica. Cada ovário foi medido nos dois eixos mais longos e todos os folículos visíveis foram quantificados. O estágio do ciclo estral foi classificado de acordo com a morfologia de cada ovário em: anestro, quando não há presença de corpo lúteo $(\mathrm{CL})$ ou folículos visíveis maiores que $2 \mathrm{~mm}$ de diâmetro; folicular, quando existia a presença de folículos de $2-10 \mathrm{~mm}$ de diâmetro e luteal quando um ou mais CL estavam presentes no ovário (Otoi et al., 2002).

Posteriormente, os ovários da fase luteal e em anestro foram fatiados e os ovários da fase folicular foram divididos em três grupos com diferentes métodos de recuperação de oócitos (Figura 1):

Primeiro ovário - Grupo PUN: punção dos folículos com agulha $25 \times 7 \mathrm{~mm}$ acoplada à uma seringa descartável $(3 \mathrm{~mL})$ contendo solução fosfata tamponada (PBS; pH neutro, temperatura ambiente, contendo cloreto de sódio, fosfato sódio e fosfato sódio monobásico); Grupo PUN+FAT: fatiamento do mesmo ovário já puncionado anteriormente no grupo PUN;

Segundo ovário - Grupo FAT: a recuperação foi feita somente a partir do fatiamento do ovário.

As estruturas recuperadas a partir de cada técnica foram mantidas separadamente em placas de Petri (Oled, São José dos Pinhais, Brasil) siliconadas. Posteriormente, os oócitos foram observados sob estereomicroscópio (Opton, Anatomic, São Paulo, Brasil), quantificados e classificados de acordo com as características morfológicas em Graus I, II e III. Em Grau I, o oócito apresentava pigmentação citoplasmática escura, com uma ou mais camadas de células do cumulus; Grau II, sua pigmentação era clara, com camadas incompletas de células do cumulus e Grau III, sua pigmentação era pálida, o oócito não apresentava formato definido e/ou sem células do cumulus conectadas, considerados degenerados (Hewitt e England, 1997).

\section{Experimento 2 - Gatas}

A coleta dos ovários foi feita após a OSH e imediatamente estes foram submetidos à avaliação morfológica. Como nas cadelas, cada ovário foi medido nos dois eixos mais longos e todos os folículos visíveis foram quantificados. A fase do ciclo estral foi classificada em: inativa, que é o período em que a atividade ovariana é reduzida não existindo a presença de corpo lúteo $(\mathrm{CL})$ e folículos maiores que $2 \mathrm{~mm}$ de diâmetro; folicular, período em que há o crescimento dos folículos, apresentando folículos iguais ou maiores que $2 \mathrm{~mm}$ de diâmetro em pelo menos um ovário; e luteal, período que ocorre após a ovulação, com presença de CL em um ou ambos os ovários (Uchikura et al., 2011).

Os mesmos três grupos experimentais foram formados e os oócitos transferidos individualmente para placas de Petri. Os oócitos foram quantificados e classificados de acordo com as características morfológicas em Graus I, II, III e IV. Os oócitos Grau I ou excelentes - possuíam ooplasma enegrecido e homogêneo, com cinco ou mais camadas de células do cumulus; Grau II ou 
bons - apresentavam citoplasma enegrecido e homogêneo, com corona radiata completa e de duas a quatro camadas de células do cumulus; Grau III ou razoáveis - apresentavam citoplasma heterogêneo com áreas de fragmentação, corona radiata completa ou não e poucas camadas de células do cumulus não compactadas; Grau IV ou degenerados - apresentavam grande transparência e fragmentação do citoplasma e ausência de corona radiata e células do cumulus (Wood e Wildt, 1997).

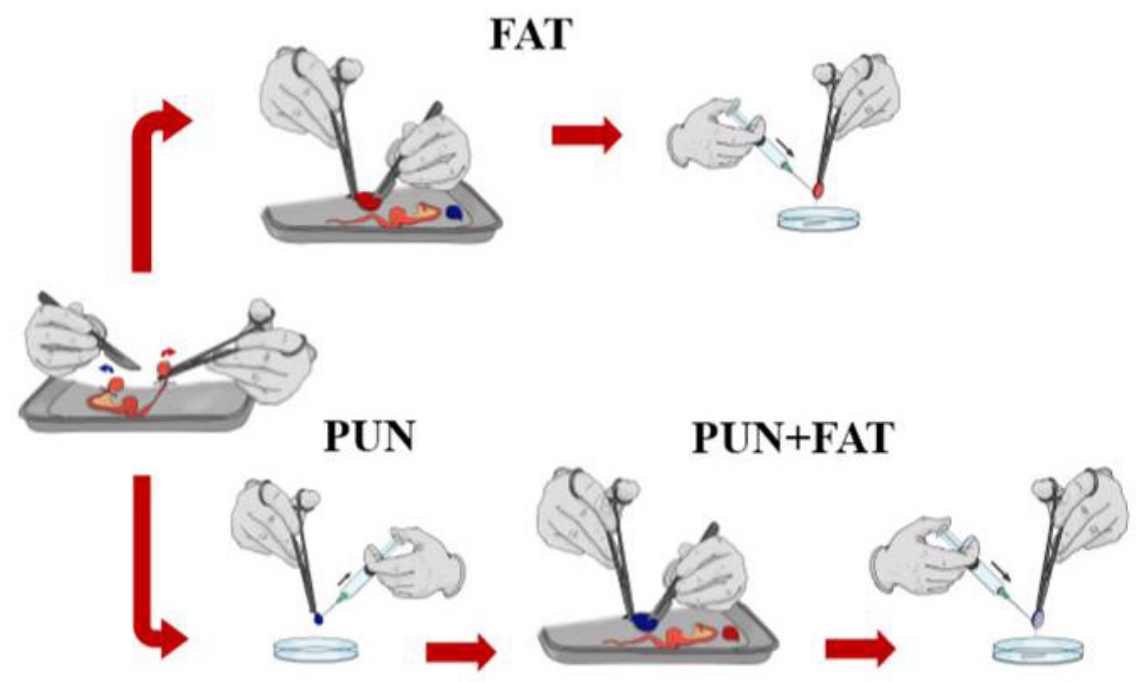

Figura 1: Esquema representativo dos grupos experimentais demonstrando as diferentes técnicas de recuperação dos oócitos na fase folicular, sendo PUN (punção dos folículos), PUN+FAT (fatiamento dos ovários que foram anteriormente puncionados) e FAT (somente fatiamento do outro ovário). Esta técnica foi aplicada para gatas e cadelas.

\section{Análise estatística}

As seguintes variáveis foram obtidas em ambas as espécies: porcentagem de fêmeas em anestro, fase folicular ou luteal; tamanho dos ovários em cada estágio do ciclo; quantidade de folículos visíveis por fêmea; quantidade e qualidade de oócitos recuperados em cada técnica; tamanho dos ovários de acordo com o porte da cadela; e quantidade e qualidade de oócitos recuperados em função do porte e idade das fêmeas caninas. Dados não paramétricos foram comparados pelo teste do Qui-quadrado, enquanto os paramétricos foram submetidos à análise de variância, e as médias foram testadas pelo teste de Tukey, pelo programa BioEstat 5.0. O nível de significância utilizado foi de $5 \%$. Todos os dados estão apresentados como média \pm DP.

\section{Resultados}

\section{Experimento 1 - Cadelas}

\section{Morfologia dos ovários}

Os ovários das fêmeas da espécie canina mediram 14,5 $\pm 0,5$ $\mathrm{mm}$ (largura) na fase folicular; 13,9 \pm 0,5 mm no anestro; e 14,5 \pm
$0,1 \mathrm{~mm}$ na fase luteal. As médias entre os portes foram: pequeno $12,0 \pm 0,6 \mathrm{~mm}$ (largura) e médio 15,7 \pm 0,3 $\mathrm{mm}$ (largura).

\section{Influência do porte do animal}

Das 35 cadelas utilizadas neste estudo, 27 foram pesadas e separadas de acordo com o porte. Destas, $52 \%(n=14)$ eram de porte pequeno e $48 \%(n=13)$ de porte médio. Não houve diferença $(P>0,05)$ na quantidade de oócitos obtidos em relação ao porte do animal: pequeno $(29,0 \pm 3,9)$ e médio $(27 \pm 2,3)$. Entretanto, houve uma tendência $(P=0,09)$ na obtenção de oócitos de boa qualidade (Grau I e II) nos diferentes portes: $72 \%$ (pequeno) versus 66\% (médio).

Influência da técnica de coleta

Quanto aos métodos de coleta, nas fêmeas em fase folicular, a técnica de FAT e PUN+FAT não apresentaram diferença na quantidade de oócitos recuperados entre si e foram superiores a técnica de PUN (Tabela 1). Com relação à qualidade, as técnicas resultaram em valores similares $(P>0,05)$ de oócitos de boa qualidade, enquanto os demais eram de baixa qualidade ou degenerados (Tabela 1). A técnica de PUN obteve uma taxa de recuperação média de67\% (12/18). Independentemente da técnica e do estágio do ciclo estral, foram obtidos um total 940 oócitos ( 27 oócitos/animal).

Influência da fase do ciclo estral

Com relação à fase do ciclo estral, 66\% (23/35) das cadelas estavam em anestro, $31 \%(11 / 35)$ em fase folicular e $3 \%(1 / 35)$ em fase luteal. Não foi possível fazer a comparação entre a fase luteal e as demais devido à baixa quantidade de animais nesta fase. Entre o anestro e a fase folicular não houve diferença $(P>0,05)$ na quantidade total de oócitos recuperados (Tabela 1). Assim como não houve diferença $(P>0,05)$ na obtenção de oócitos de boa qualidade entre todas as fases (Tabela 1).

\section{Influência da idade}

A idade da cadela influenciou tanto na quantidade, como na qualidade dos oócitos recuperados (Figura 2), sendo a idade de três anos superior na obtenção de oócitos em boa quantidade e qualidade. Por outro lado, as cadelas de oito anos apresentaram maior quantidade de oócitos de baixa qualidade, ou seja, Grau III $(P<0,05)$.

\section{Experimento 2 - Gatas}

Morfologia dos ovários

Os ovários das fêmeas felinas mediram $11 \pm 2 \mathrm{~mm}$ (largura) na fase folicular; $11 \pm 1 \mathrm{~mm}$ (largura) na luteal; e $11 \pm 1 \mathrm{~mm}$ (largura) na inativa. 

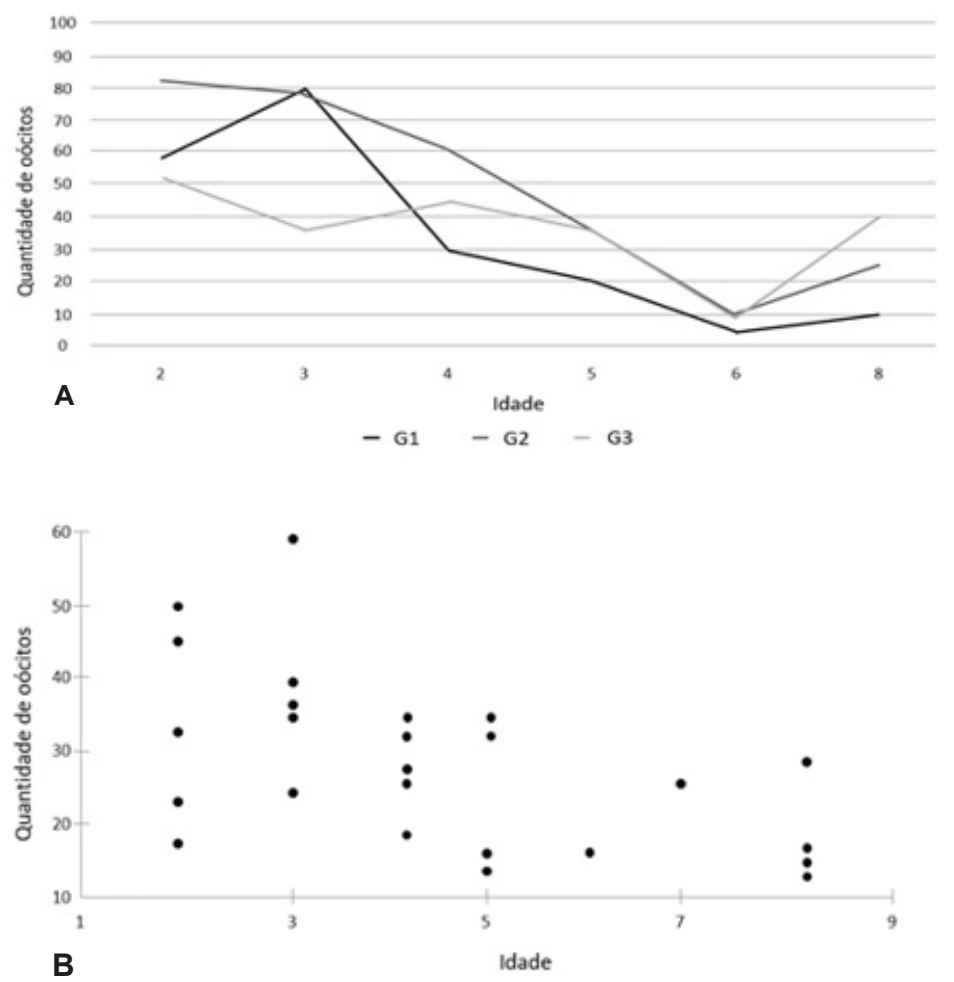

Figura 2: Influência da idade da cadela na quantidade e qualidade de oócitos recuperados após ovariosalpingohisterectomia $(\mathrm{OSH})$. [A] O efeito da idade do animal (de dois a oito anos) na recuperação de oócitos de boa qualidade (GI e II) ou de baixa qualidade (GIII). [B] Correlação linear de Pearson entre a idade da cadela e a quantidade de oócitos recuperados.
Influência da técnica de coleta

Nas fêmeas em fase folicular foram recuperados 476 oócitos. As técnicas de PUN+FAT (177/476) e FAT (244/476) recuperaram número semelhante $(P>0,05)$ de oócitos entre si e maior quantidade $(P<0,05)$ de oócitos do que PUN (55/476) (Tabela 1). A taxa média de recuperação em PUN foi de 79\% (55/70). Quanto à qualidade, não houve diferença $(P>0,05)$ entre as técnicas de coleta (Tabela 1). Independentemente da técnica e da fase do ciclo estral, foram obtidos um total de 974 oócitos ( 23 oócitos/animal).

Influência da fase do ciclo estral

Com relação à fase do ciclo estral, 46,5\% (20/43) dos animais estavam na fase folicular, 21,0\% (9/43) na luteal e $32,5 \%$ (14/43) na inativa. Dos 43 pares de ovários utilizados, em 41 a recuperação dos oócitos ocorreu nas estações de Outono e Inverno (período com menos horas de luz disponível, sugestivo de anestro estacional) e apenas dois pares na Primavera (estação reprodutiva). Todas as gatas em que os ovários não apresentaram folículos maiores que $2 \mathrm{~mm}$, estavam no Outono e Inverno. Não houve diferença ( $P>0,05)$ na quantidade de oócitos recuperados em cada fase (Tabela 1). Contudo, em relação à qualidade, a fase inativa mostrou-se superior à luteal $(P<0,05)$ e semelhante $(P>0,05)$ à folicular na quantidade de oócitos de melhor qualidade. Na comparação entre as fases folicular e luteal, não foi constatada diferença $(P>0,05)$ na recuperação de oócitos de boa qualidade (Tabela 1).

Tabela 1: Quantidade (Média \pm DP) e qualidade de oócitos recuperados após a realização de diferentes técnicas de coleta em fêmeas caninas e felinas em fases variadas do ciclo estral

\begin{tabular}{|c|c|c|c|c|}
\hline Espécie & & & Quantidade & Boa Qualidade (\%) \\
\hline \multirow{6}{*}{ Canina } & \multirow{4}{*}{ Técnica** } & FAT $^{* * * *}$ & $13 \pm 6,7^{a}$ & $70,0^{a}$ \\
\hline & & $\mathrm{PUN}^{* * *}$ & $1 \pm 1,4^{b}$ & $83,0^{a}$ \\
\hline & & PUN+FAT ${ }^{*+*+*}$ & $15 \pm 8,0^{a}$ & $74,0^{\mathrm{a}}$ \\
\hline & & Folicular & $28 \pm 14,3^{a}$ & $72,5^{a}$ \\
\hline & \multirow[t]{3}{*}{ Fase } & Inativo & $26 \pm 9,8^{a}$ & $67,0^{\mathrm{a}}$ \\
\hline & & Luteal & $33^{* *}$ & $48,5^{a}$ \\
\hline \multirow{6}{*}{ Felina } & & FAT $^{* * * *}$ & $12,2 \pm 8,3^{a}$ & $30,7^{a}$ \\
\hline & \multirow[t]{3}{*}{ Técnica** } & $\mathrm{PUN}^{* * * *}$ & $2,7 \pm 2,5^{b}$ & $40,0^{a}$ \\
\hline & & PUN+FAT $T^{* * * *}$ & $8,8 \pm 5,1^{\mathrm{a}}$ & $26,0^{a}$ \\
\hline & & Folicular & $24 \pm 13,8^{a}$ & $30,0^{a, b}$ \\
\hline & \multirow[t]{2}{*}{ Fase } & Inativo & $26 \pm 23,6^{a}$ & $34,0^{\mathrm{b}}$ \\
\hline & & Luteal & $14 \pm 8,2^{\mathrm{a}}$ & $22,0^{a}$ \\
\hline
\end{tabular}

Valores com o mesmo sobrescrito não apresentam diferença significativa. "Óocitos classificados em graus I e II.

"Comparação entre as técnicas de coleta na fase folicular.

"*Não obteve número suficiente para comparação.

***** PUN (punção dos folículos), PUN+FAT (fatiamento dos ovários que foram anteriormente puncionados) e FAT (somente fatiamento do outro ovário) 


\section{Discussão}

O procedimento de $\mathrm{OSH}$ é um importante método de controle populacional e controle de patologias relacionadas ao trato reprodutivo (Howe, 2006). Esta técnica torna-se então uma fonte de grande quantidade de ovários a baixo custo, justificando o uso do modelo de felinos e caninos domésticos para a pesquisa básica. Entretanto, a execução da OSH não é recomendada para esses animais durante o período folicular, devido ao aumento da vascularização do trato reprodutor, elevando os riscos de hemorragia durante o procedimento cirúrgico (Reynaud et al., 2004). Consequentemente, grande parte dos animais submetidos à OSH deveriam estar em fase inativa ou luteal. No entanto, vale salientar que 20 fêmeas da espécie felina e 11 da canina em fase folicular foram submetidos a esse procedimento, por seus tutores, durante este estudo e, portanto, $46,5 \%$ das gatas e $31,0 \%$ das cadelas.

A literatura até o momento não apresentava uma comparação direta que permitisse avaliar o potencial de recuperação entre as duas técnicas de coleta nos felinos e caninos domésticos. A taxa de recuperação de oócitos em felinos após PUN foi de $79 \%$ e nos caninos de $67 \%$; esses valores podem ser considerados altos quando comparados às taxas obtidas pela mesma técnica nas espécies caprina (74,3\%; Souza et al., 2013), ovina (71,6\%; Teixeira et al., 2015$)$ e bovina $(77,1 \%$; Currin et al., 2017), principalmente em função do reduzido tamanho dos ovários de ambas as espécies. No entanto, em gatas e cadelas na fase folicular, a PUN foi responsável por apenas $11,5 \%$ e $4,0 \%$ do total de oócitos, respectivamente. Estes valores foram significativamente inferiores aos obtidos após FAT ou PUN+FAT $(37,2$ a 52,0\%). Isto demonstra que o uso de FAT é superior em obter maior quantidade de oócitos que a PUN, assim como descrito anteriormente em caprinos (Martino et al., 1994; John et al., 2015). A superioridade de FAT ocorre provavelmente, pois durante sua execução são recuperados oócitos de camadas mais profundas do ovário (folículos pré-antrais), enquanto PUN recupera apenas aqueles presentes na superfície, ou seja, antrais (Das et al., 1996). Isso justifica ainda a ausência de diferença na quantidade de oócitos recuperados em diferentes fases em ambas as espécies no presente experimento.

Não foi encontrado na literatura estudos que comparam diretamente o efeito de diferentes técnicas de recuperação na qualidade dos oócitos nessas espécies. A obtenção de oócitos de boa qualidade em outras espécies é uma das características da técnica de PUN quando comparada à de FAT (Martino et al., 1994; John et al., 2015). Entretanto, no presente estudo, as técnicas de PUN e FAT não apresentaram diferença na quantidade de oócitos de boa qualidade recuperados tanto nas fêmeas felinas como nas caninas. Johnston et al. (1989) e Karja et al. (2002) recuperaram na espécie felina uma média de 20 oócitos de boa qualidade, utilizando PUN e FAT, respectivamente. Em cadelas, não foi encontrado na literatura a comparação para avaliar o potencial de recuperação de oócitos de ambas as técnicas.

Com relação à influência da fase do ciclo estral na espécie felina, foi verificado que a fase luteal influencia negativamente na recuperação de oócitos de boa qualidade em relação à fase inativa. Resultados similares foram obtidos anteriormente por
Freistedt et al. (2001). O ambiente hormonal predominante nas fêmeas na fase inativa difere completamente das fêmeas em fase folicular e luteal (Wildt et al., 1981), o que pode influenciar na competência dos oócitos em desenvolvimento. Essa menor quantidade de oócitos pode ser explicada devido ao efeito dominante da progesterona existente nesta fase do ciclo, proveniente da presença de CL. Em gatas, a progesterona possui efeito adverso na competência dos folículos em desenvolvimento, impedindo que um maior número de oócitos alcance uma boa qualidade, promovendo sua atresia (Johnston et al., 1989; Wood et al., 1997). Este tema vem sendo estudado nos últimos anos em felinos domésticos (Freistedt et al., 2001; Comizzoli et al., 2003; Reynauld et al., 2009; Carreiro et al., 2018), assim como em outras espécies que apresentam sazonalidade reprodutiva (Duarte et al., 2008; Williams et al., 2012). Entretanto, nos estudos conduzidos por Spindler e Wildt (1999), Martins (2009) e Carreiro et al. (2018) não foi encontrada influência da fase do ciclo da recuperação de oócitos de boa qualidade. Talvez outros fatores podem estar influenciando nestas diferenças entre os estudos citados, como as concentrações de progesterona (Rodrigues et al., 2009), ou até mesmo a nutrição, fotoperíodo do local e raça.

Já nas fêmeas da espécie canina, não houve diferença entre as fases do ciclo na recuperação de oócitos de boa qualidade, corroborando com Binsfeld et al. (2014) e Carreiro et al. (2018). Já Apparicio-Ferreira (2010) observou que a fase folicular recuperou número maior de oócitos de melhor qualidade. Em função dos resultados contraditórios na literatura sobre a relação entre o ciclo estral e a quantidade de oócitos de boa qualidade em cadelas, fazem-se necessários novos estudos para que sejam estabelecidos padrões corretos na espécie canina.

A idade das fêmeas caninas apresentou influência na quantidade e qualidade dos oócitos recuperados, onde as de três anos foram superiores e as de oito anos foram inferiores às demais. Estes dados corroboram os resultados de Luvoni et al. (2005), que a idade da cadela influencia negativamente na quantidade de oócitos recuperados com o passar dos anos. Similarmente, Farstad (2000) e Rocha et al. (2006) demonstraram que cadelas mais jovens possuem oócitos de melhor qualidade do que as cadelas consideradas idosas. De acordo com Armstrong (2001) a queda da fertilidade com o avanço da idade é comum nos mamíferos, tendo como principais fatores a redução da receptividade do aparelho reprodutor e a redução da reserva folicular e consequentemente de oócitos.

O porte das cadelas não influenciou a quantidade de oócitos recuperados. Porém, houve uma tendência nas fêmeas de porte pequeno apresentar oócitos de melhor qualidade. $\mathrm{Na}$ literatura consultada, não foram encontrados relatos sobre a influência do porte da cadela na quantidade e qualidade de oócitos recuperados. Desta forma, a hipótese de que cães de porte maior apresentariam a contagem da população folicular mais elevada, subsequentemente maior número de oócitos e maior número de crias ao parto, não foi confirmada no presente estudo. Possivelmente, o maior número de crias obtido em cães de porte maior pode estar relacionado ao maior espaço uterino para o desenvolvimento dos fetos. 


\section{Conclusão}

Os resultados encontrados no presente estudo indicam que a técnica de fatiamento recupera maior quantidade de oócitos, não influenciando em sua qualidade. As fases inativa e folicular recuperam maior quantidade de oócitos de boa qualidade em gatas e não afetam a recuperação em cadelas. Portanto, para otimizar o uso das biotecnologias, deve-se levar em consideração o estágio do ciclo estral em fêmeas felinas e a técnica de coleta utilizada na recuperação de oócitos.

\section{Agradecimentos}

ROC foi bolsista PIBIC pelo Programa Santander Universidades, bolsista TCT da FAPERJ e JMGSF é bolsista jovem cientista da FAPERJ. Agradecemos ainda à Isabel Côrrea pela parte artística e à toda a equipe do Hospital-Escola de Medicina Veterinária Prof. Allan Kardec.

\section{Referências}

ARMSTRONG, D.T. Effects of maternal age on oocyte developmental competence. Theriogenology, v.55, p.1303-1322, 2001.

BALDASSARRE, H.; WANG, B; KAFIDI, N; KEEFER, C; LAZARIS, A; KARATZAS, C.N. Advances in the production and propagation of transgenic goats using laparoscopic ovum pick-up and in vitro embryo production technologies. Theriogenology, v.57, p. $275-284,2002$.

BINSFELD, L.C.; DARRIBA, R.V.; BORGES, J.L.; OTUTUMI, L.K.; SANTOS, I.W.; LEAL, L.S. Avaliação ovariana morfométrica e recuperação dos complexos Cumulus oophorus de cadelas em diferentes fases do ciclo estral. Archives of Veterinary Science, v.19, p.31 - 39, 2014.

BROWN, J.L. Female reproductive cycles of wild female felids. Animal Reproduction Science, v.124, p.155-162, 2011.

CARREIRO, A.N.; SOUZA, J.G.; LA SALLES, A.Y.F.; FALCÃO, B.M.R.; ARAÚJO, D.V.B.; DINIZ, J.A.R.A.; ROCHA, E.F.; ARAÚJO, N.L.S.; MENEZES, D.J.A. Obtenção de oócitos em cadelas e gatas submetidas a ovariosalpingohisterectomia. Pubvet, v.12, p.1-6, 2018.

COMIZZOLI, P, WILDT, D.E.; PUKAZHENTHI, B.S. Overcoming poor invitro nuclear maturation and developmental competence of domestic cat oocytes during the non-breeding season.

Reproduction, v.126, p.809-816, 2003.

CURRIN, L.; MICHALOVIC, L.; BELLEFLEUR, A.M.; GUTIERREZ, K, GLANZNER, W.; SCHUERMANN, Y.; BOHRER, R.C.; DICKS, N.; DA ROSA, P.R.; DE CESARO, M.P.; LOPEZ, R.; GRAND, F.X.; VIGNEAULT, C.; BLONDIN, P.; GOURDON, J.; BALDASSARRE, H.; BORDIGNON, V. The effect of age and length of gonadotropin stimulation on the in vitro embryo development of Holstein calf oocytes, Theriogenology, v.104, p.87 - 93, 2017.

DAS, G.K.; JAIN, G.C.; SOLANKI, V.S.; TRIPATHI, V.N. Efficacy of Various Collection Methods for Oocyte Retrieval in Buffalo. Theriogenology, v.46, P.1403 - 1411, 1996.

DRISCOLL, C.A.; MENOTTI-RAYMOND, M.; ROCA, A.L.; HUPE, K.; JOHNSON, W.E.; GEFFEN, E.; HARLEY, E.H.; DELIBES, M.; PONTIER, D.; KITCHENER, A.C.; YAMAGUCHI, N.; O'BRIEN, S.J.; MACDONALD, D.W. The Near Eastern Origin of Cat Domestication. Science, v.317, p.519-523, 2007

DUARTE, G.; FLORES, J.A.; MALPAUX, B.; DELGADILLO, J.A. Reproductive seasonality in female goats adapted to a subtropical environment persists independently of food availability. Domestic Animal Endocrinology, v.35, p.362 - 370, 2008.

FARACO, C.B. Interação Humano-Animal. Ciência Veterinária nos Trópicos, v. 11, p.31-35, 2008.
FARSTAD, W. Current state in biotechnology in canine and feline reproduction. Animal Reproduction Science, v. 60 - 61, p. 375 - 387, 2000.

FREISTEDT, P.; STOJKOVIC, M.; WOLF, E. Efficient in vitro production of cat embryos in modified synthetic oviduct fluid medium: effects of season and ovarian status. Biology of Reproduction, v.65, p.9-13, 2001.

HERMANSSON, U.; AXNÉR, E.; HOLST, B.S. Application of a zona pellucida binding assay (ZBA) in the domestic cat benefits from the use of in vitro matured oocytes. Acta Veterinaria Scandinavica, v.49, p.28, 2007.

HOWE, L.M. Surgical methods of contraception and sterilization. Theriogenology, v. 66, p.500-509, 2006.

HEWITT, D.A.; ENGLAND, G.C.W. The effect of oocyte size and bitch age upon oocyte nuclear maturation in vitro. Theriogenology, v.49, p.957 - 966, 1998.

JEWGENOW, K.; BRAUN, B.C.; DEHNHARD, M.; ZAHMEL, J.; GOERITZ, F. Research on reproduction is essential for captive breeding of endangered carnivore species. Reproduction in Domestic Animals, v. 52, p. 18-23, 2017.

JOHN, A.; JOSEPH, M.; VIJAYAKUMARAN, V.; MANOJ, C.J. Effect of oocyte retrieval techniques on yield and quality of caprine oocytes. Journal of Agriculture and Veterinary Science, v.8, p.50 $-52,2015$.

JOHNSTON, L.A.; O'BRIEN, S.J.; WILDT, D.E. In vitro maturation and fertilization of domestic cat follicular oocytes. Gamete Research, v.24, p.343 - 356, 1989.

JOHNSTON, S.D.; KUSTRITZ, M.V.R.; OLSON, P.N.S. Canine and feline theriogenology. W.B. Saunders Company, p.16-31, 2001.

KARJA, N.W.K.; OTOI, T.; MURAKAMI, M.; FAHRUDIN M.; SUZUKI T. In vitro maturation, fertilization and development of domestic cat oocytes recovered from ovaries collected at three stages of the reproductive cycle. Theriogenology, v.57, p.22892298, 2002.

LASIENË, K.; VITKUS, A.; VALANĖIÛTË, A.; LASYS, V. Morphological criteria of oocyte quality. Medicina, v.45, p.509, 2009.

MARTINO, A.; PALOMO, M.J.; MOGAS, T.; PARAMIO, M.T. Influence of the collection technique of prepubertal goat oocytes on in vitro maturation and fertilization. Theriogenology, v.42, p.859 $-873,1994$.

MARTINS, L.R. Influência da sazonalidade e da condição ovariana sobre a produção embrionária in vitro de gato doméstico (Felis catus, Linnaeus, 1758). Tese (doutorado) - Universidade Estadual Paulista, Faculdade de Medicina Veterinária e Zootecnia, Botucatu, 2008. 
MORO, L.N.; HIRIART, M.I.; BUEMO, C.; JARAZO, J.; SESTELO A.; VERAGUAS, D.; RODRIGUEZ-ALVAREZ, L.; SALAMONE, D.F. Cheetah interspecific SCNT followed by embryo aggregation improves in vitro development but not pluripotent gene expression. Reproduction, v.150, p.1 - 10, 2015.

MÜLLER, D.C.M. Adaptação do índice de massa corporal humano para cães. Dissertação (mestrado) - Universidade Federal de Santa Maria, Rio Grande do Sul, 2007.

NAGANO, M.; UCHIKURA, K.; TAKAHASHI, Y.; HISHINUMA, M. Effect of duration of in vitro maturation on nuclear maturation and fertilizability of feline oocytes. Theriogenology, v.69, p.231 - 236, 2008.

OTOI, T.; WILLINGHAM, L.; SHIN T.; KRAEMER D.C.; WESTHUSIN W. Effects of oocyte culture density on meiotic competence of canine oocytes. Reproduction, v. 124 (6), p. $775-$ 781, 2002.

PEREIRA, A.F.; FELTRIN, C.; ALMEIDA, K.C.; CARNEIRO, I.S.; AVELAR, S.R.G.; NETO, A.S.A.; SOUSA, F.C.; MELO, C.H.S.; MOURA, R.R.; TEIXEIRA, D.I.A.; BERTOLINI, L.R.; FREITAS, V.J.F.; BERTOLINI, M. Analysis of factors contributing to the efficiency of the in vitro production of transgenic goat embryos (Capra hircus) by handmade cloning (HMC). Small Ruminant Research, v. 109, p. $163-172,2013$.

REYNAUD, K.; SAINT-DIZIER, M.; CHASTANT-MAILLARD, S. In vitro maturation and fertilization of canine oocytes. Methods in Molecular Biology, v. 253, p. 255 - 272, 2004.

RODRIGUES, B.A.; RODRIGUEZ, P.; SILVA, A.E.F.; CAVALCANTE, L.F.; FELTRIN, C.; RODRIGUES, J.L. Preliminary Study in Immature Canine Oocytes Stained with Brilliant Cresyl Blue and Obtained From Bitches with Low and High Progesterone Serum Profiles. Reproduction in Domestic Animals, v. 44, p. 255258, 2009.

ROCHAA, A.A.; BASTOS, R.; CUNHA, I.C.N.; ADONA, P.R.; SANTOS, J.A. Quantity and quality of oocytes recovered from donor bitches of different ages. Theriogenology, v. 66, p. $1465-$ 1467, 2006

SOUZA-FABJAN, J.M.G.; PEREIRA, A.F.; MELO, C.H.S.; SANCHEZ, D.J.D.; OBA, E.; MERMILLOD, P.; MELO, L.M.; TEIXEIRA, D.I.A.; FREITAS, V.J.F. Assessment of the reproductive parameters, laparoscopic oocyte recovery and the first embryos produced in vitro form endangered Canindé goats (Capra hircus). Reproductive Biology, v.13, p.325 - 332, 2013.

SOWIŃSKA, N.; FRANKOWSKA, K.; FILIPCZYK, A.; ADAMASZEK, A.; NALIK, K.; FIC, K.; PIETSCHFULBISZEWSKA, A. The effect of cumulus cells on domestic cat (Felis catus) oocytes during in vitro maturation and fertilization. Reproduction in Domestic Animals, v.52 (Suppl. 2), p.108 - 113, 2017.
SPINDLER, R.E.; WILDT, D.E. Circannual variations in intraovarian oocyte but not epididymal sperm quality in the domestic cat. Biology of Reproduction, v.61, p.188 - 194, 1999.

TEIXEIRA, P.P.M.; PADILHA, L.C.; SILVA, A.S.L.; BARROS, F.F.P.C.; COUTINHO, L.N.; SILVA, M.A.M.; FLÔRES, F.N.; LOPES, M.C.S.; VRISMAN, D.P.; CONCEIÇÃO, M.E.B.A.M.; VICENTE, W.R.R. Ovum pick-up technique in recently weaned ewe lambs subjected to ovarian stimulation. Acta Scientiae Veterinariae, v.43, p.1 - 9, 2015.

UCHIKURA, K.; NAGANO, M.; HISHINUMA, M. Evaluation of Follicular Development and Oocyte Quality in Pre-pubertal Cats. Reproduction in Domestic Animals, v.45, p.405 - 411, 2010.

UCHIKURA, K.; NAGANO, M.; HISHINUMA, M. The effect of ovarian status and follicular diameter on maturation ability of the domestic cat. Journal of Veterinary Medicine Science, v. 73(5), p.561 - 566, 2011.

WILDT, D.E.; COMIZZOLI, P.; PUKAZHENTHI, B.; SONGSASEN, $\mathrm{N}$. Lessons from biodiversity - the value of nontraditional species to advance reproductive science, conservation, and human health. Molecular reproduction \& development, v.77, p.397 - 409, 2010.

WILDT, D.E.; CHAN, S.Y.W.; SEAGER, S.W.J.; CHAKRABORTY, P.K. Ovarian activity, circulating hormones, and sexual behavior in the cat. I. Relationships during the coitus-induced luteal phase and the estrous period without mating. Biology of Reproduction, v. 25, p. $15-28,1981$

WILLIAMS, G.L.; THORSON, J.F.; PREZOTTO, L.D.; VELEZ, I.C.; CARDOSO, R.C.; AMSTALDEN, M. Reproductive seasonality in the mare: neuroendocrine basis and pharmacologic control. Domestic Animal Endocrinology, v.43, p.103 - 115, 2012.

WOOD, T.C.; WILDT, D.E. Effect of the quality of the cumulusoocyte complex in the domestic cat on the ability of oocytes to mature, fertilize and develop into blastocysts in vitro. Journal of Reproduction and Fertility, v.110, p.355 - 360, 1997.

WOOD, T.C.; MONTALI, R.J.; WILDT, D.E. Follicle-oocyte atresia and temporal taphonomy in cold-stored domestic cat ovaries. Molecular Reproduction and development, v.46, p.190 - 200, 1997. 